\title{
The use of large volume, transparent, enclosed sea-surface water columns in the study of stress on plankton ecosystems
}

\author{
G. D. Grice ${ }^{1}$, M. R. Reeve ${ }^{2}$, P. KoelleR ${ }^{3} \&$ D. W. Menzel ${ }^{4}$ \\ 1 Woods Hole Oceanograpbic Institution; \\ Woods Hole, Massachusetts, USA, \\ ${ }^{2}$ Rosenstiel School of Marine and Atmospheric Science, University of Miami; \\ Miami, Florida, USA, \\ ${ }^{3}$ Institute of Oceanography, University of British Columbia; \\ Vancouver, British Columbia, Canada, \\ and \\ 4 Skidaway Institute of Oceanography, University System of Georgia; \\ Savannah, Georgia, USA
}

\begin{abstract}
A brief account is given of the Controlled Ecosystem Pollution Experiment (CEPEX) program, with results from a recent experiment designed to ascertain effects of mercury on planktonic ecosystems. The experimental modules are $1300 \mathrm{~m}^{3}$ transparent, flexible, polyethylene cylinders $9.5 \mathrm{~m}$ in diameter and $23.5 \mathrm{~m}$ deep, floating for periods up to three months at the sea surface of Saanich Inlet, British Columbia. Groups of three cylinders are filled simultaneously by being raised to the surface from $35 \mathrm{~m}$, a procedure shown to produce biological replicability. An experiment is described in which mercury at 1 and $5 \mu \mathrm{g}^{-1}$ was added to two modules, with a third serving as a control. In both polluted modules temporary reductions in heterotrophic activity of micro-organisms and carbon assimilation of phytoplankton were observed, followed by a return to control levels. Only at the higher mercury concentration were any effects observed in the zooplankton, which included reduced feeding in Calanus, mortality and molting failure of Pseudocalanus and decreased growth in young fish.
\end{abstract}

\section{INT'RODUCTION}

The study of the ecology of the water column in the marine environment presents a combination of logistical problems not encountered in most other environments. Foremost amongst the physical problems are the nature of the medium (seawater), which is in continuous motion, and the usually inconveniently large size of the study area. It is impractical to expect to return to the same place on successive occasions and follow population changes resulting only from the passage of time, unblurred by mixing processes. The bulk of the biomass is microscopically small, but not small enough for generation times to be measured in minutes and hours, or for standard 
microbiological laboratory techniques to be applicable. The animal component, in particular, requires weeks or months to complete a life cycle, is often accustomed to traveling large vertical and horizontal distances, and rarely does well in a laboratory situation where confinement and progressive alteration of its medium produce an unnatural, if not highly stressed, situation.

\section{CEPEX PROGRAM}

It is hardly surprising that water column ecologists have frequently sought to eliminate population mixing by confining relatively large volumes of sea water in a state sufficiently natural for organisms to continue normal activities. Such systems appear particularly desirable where the longer term effects of pollutants at very low concentrations are to be studied, and where some comparison with "control" populations is essential. This was the conclusion reached by a group of marine scientists who were requested by the office of the International Decade of Ocean Exploration of the National Science Foundation in 1972 to investigate the effects of, and make predictions concerning, the release of pollutants into the oceanic environment. The program, designated as the Controlled Ecosystem Pollution Experiment (CEPEX) was centered around the operation of "controlled experimental ecosystem" modules (CEEs) which were large, transparent, closed-ended polyethylene bags, varying in size up to $10 \mathrm{~m}$ in diameter and $30 \mathrm{~m}$ in depth, floating at the sea surface in Saanich Inlet, British Columbia and containing up to $2,000 \mathrm{~m}^{3}$ of water.

Menzel \& Steele (1977) provided a brief comparative history of the design and use of such structures and reviewed their advantages and disadvantages. They noted that the main disadvantage of enclosed systems was the mechanical separation of the enclosed water from that outside, which severely reduced mixing forces within the internal water column. As will be detailed later, this, in itself, affects the behavior and continued survival of some groups of organisms, and means that population events do not usually closely duplicate those on the outside. These authors stressed that, from the experimental viewpoint, it is more important that enclosures can replicate each other when they are manipulated in an identical fashion. The size of enclosures depends largely on the number of trophic levels under consideration. A system containing first and second order consumers as well as producers, which is to be in operation for several months, needs to be at least $1,000 \mathrm{~m}^{3}$ in volume in order to sustain populations large enough to accommodate the nutritional requirements of the highest trophic level (e.g. juvenile fish) and the removal of material for sampling purposes. In practice, containers cannot be made large enough to study interactions affected by both temporal and spatial dimensions. Indeed, it is the spatial aspect of the ecosystem which we are seeking to minimize.

Case (1977) provided a detailed account of the evolution of the philosophy involved in this novel form of marine engineering, as well as the physical systems and their ability to withstand sea stresses. Inherent in his designs was the principle that the structures should accommodate to winds, waves and currents, rather than attempt to resist their forces. 
The first three CEEs to be tested in August, 1973 were small $(2.5 \mathrm{~m}$ diam., $16 \mathrm{~m}$ deep, $66 \mathrm{~m}^{3}$ volume) and were filled by diaphragm pump over two days. Their populations of plankton did not replicate well. By 1974, small CEEs were filled by simultaneously raising a group of 6 from a collapsed condition at a depth greater than their length. Divers, by swimming upwards with the open CEE mouth, were able to "capture" or enclose a column of water and the organisms in it. Takahashi et al. (1975) described the satisfactory replication of a suite of CEEs managed in this manner. During the summer of 1974 a series of 1-month experiments were performed examining effects of copper and hydrocarbons on captured populations. The results of these experiments were recorded in a series of papers constituting the Bulletin of Marine Science (volume 27,1). The operation and construction of these small CEEs was described by Menzel \& Case (1977) and the experiments were summarized by Menzel (1977).

Further experiments using the six small CEEs were performed in 1975 and 1976, including studies on hydrocarbons, mercury, cadmium, heavy metal combinations, nutrient enrichment (eutrophication), artificial upwelling of the water columns, and effects of removing plankton carnivores (e.g. Parsons et al., 1977; Reeve \& Walter, 1976).

From the outset, the intention was to develop larger CEEs for longer term experiments, and this proceeded concurrently and with experience gained from small CEE experiments. The prototype full-scale module was installed in September, 1974. With a volume of nearly $2,000 \mathrm{~m}^{3}(9.5 \mathrm{~m}$ diameter, $30 \mathrm{~m}$ deep) it was supported by an acrylic flotation collar. Two more units were subsequently installed at the beginning of the 1975 experimental season, but the acrylic collars of both of these broke up in early summer storms (see Case, 1977 for a structural failure analysis). Steel flotation collars were designed and put in place by August of that year and the CEEs were re-launched. On this occasion surface waters were of unusually low salinity and when conditions returned to normal the low-salinity waters captured in the CEEs caused them to float on the outside water and assume erratic shapes. Subsequent pumping out and replacement of some of the internal, low-salinity water with outside, deeper, high-salinity water restored the density balance between inside and outside. This permitted the CEEs to adopt a normal vertical attitude, but variably altered the populations within them so that biological replication did not occur. The first successful experiment with three full-scale modules took place over 70 days starting in May 1976. These modules were shortened to $23.5 \mathrm{~m}\left(1,300 \mathrm{~m}^{3}\right.$ volume $)$ and raised almost simultaneously, achieving better than $90 \%$ fill of water captured. The remaining volume was added by pumping from the same source into all three CEEs simultaneously until a slight head was achieved inside the CEEs, which imparted turgidity to the polyethylene sides.

The full-scale CEE (Fig. 1) is described in detail by Case (1977). The flexible bag, consisting of nylon-reinforced polyethylene in two layers, is attached to the upper ring of the flotation collar by about 200 rubber shock cords. Below the $16 \mathrm{~m}$ cylindrical section, the bag terminates in a $7.5 \mathrm{~m}$ conical section tapering to a $5 \mathrm{~cm}$ hose, which returns to the surface on the outside. Water can be pumped into the CEE from this hose and sediment can be pumped out as required. A series of 18 shrouds (16 mm 
polyester line), terminating in $100 \mathrm{~kg}$ weights, hang from the flotation collar. A separate dacron cone of the same dimensions as the conical base of the bag is drawn up tightly beneath the bag by means of lines attached to the shrouds, and acts as a support or cushion for the bag. The flotation collar is an 18 -sided, $0.6 \mathrm{~m}$ diameter epoxy-coated, steel tube resting on styrofoam. To start an experiment new bags are
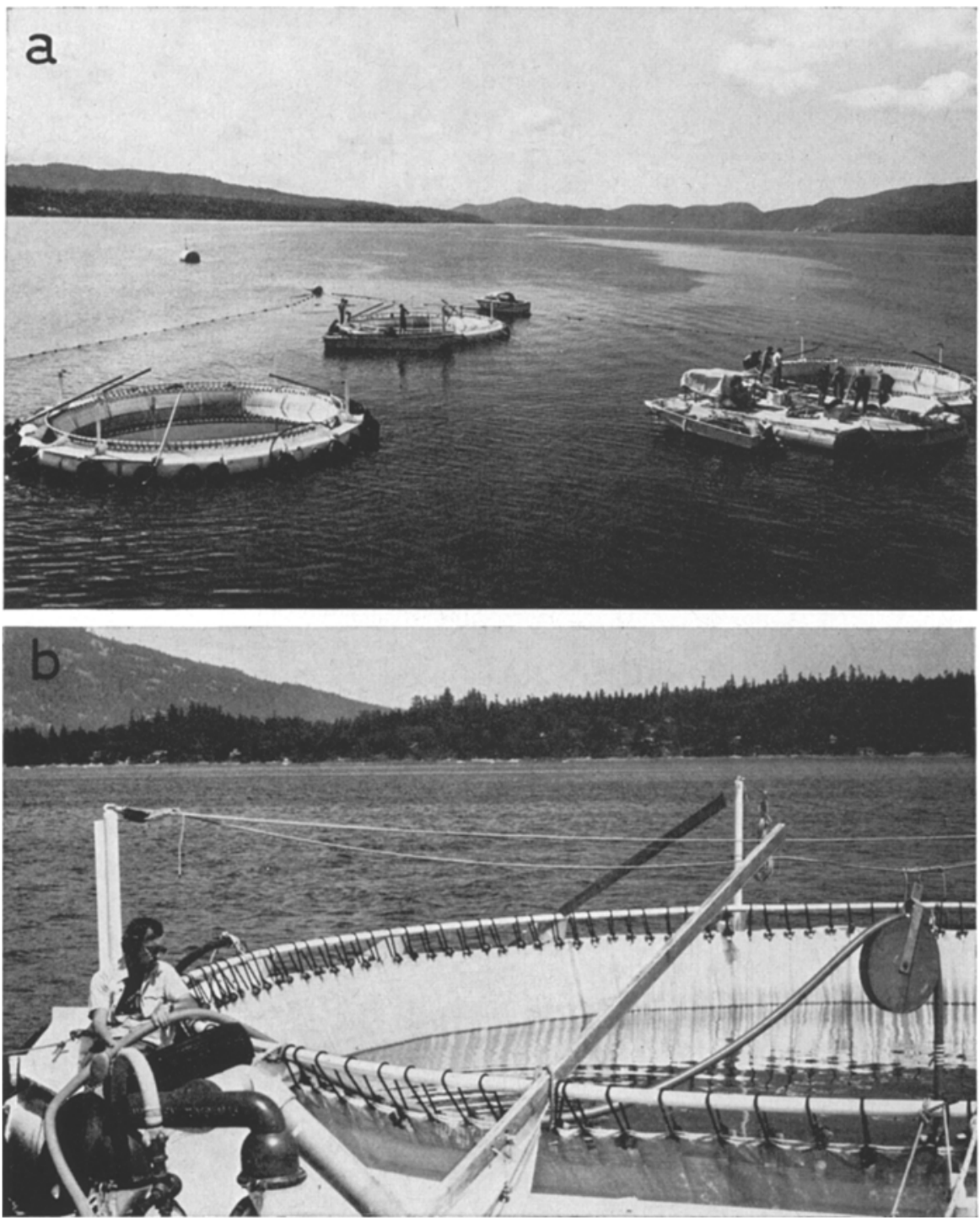

Fig. 1: (a) View of the three CEEs with central sampling platform positioned adjacent to one of them. (b) CEE with large-volume plankton sampling system in operation, with pump assembly on the sampling platform (left foreground) 


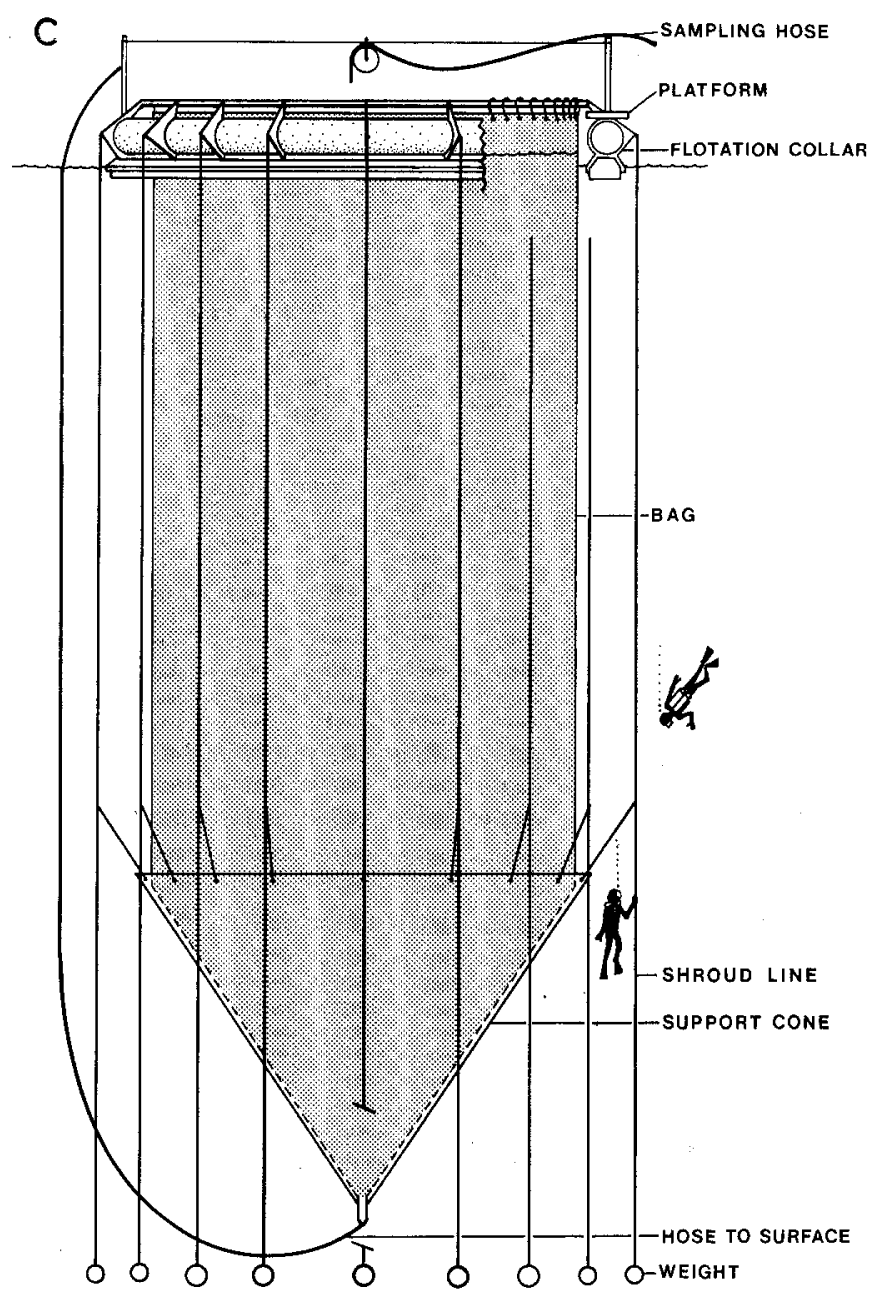

Fig. 1: (c) Diagram of the CEE showing underwater structure and suspension method

introduced into the water in the center of the flotation collar, the bag mouths attached by slip rings to the shrouds, and allowed to fall to the bottom weights of the shrouds where they remain extended overnight, or until conditions are suitable for water column capture. At that time, divers inflate a detachable plastic flotation collar around the bag mouth. This causes the entire bag to ascend, mouth-open, up the shrouds to the surface, where the temporary collar is quickly removed. The shroud connections are released and the mouth is attached to the permanent surface collar. The raising of three CEEs simultaneously may take less than six minutes. The operation is completed by attaching the hose, and pumping any water required to achieve the necessary internal head; and raising the supporting cone into position. 


\section{THE 1976 MERCURY EXPERIMENT}

\section{CEE replication and mercuryaddition}

CEEs were filled simultaneously as described in the previous paragraph and checked for uniformity over the subsequent 10 days by repeated observation and sampling of physical (salinity), chemical (nutrients), and biological (phytoplankton, zooplankton species and abundance) parameters. On May 19 mercury (in the form of $\mathrm{HgCl}_{2}$ ) was distributed in two CEEs (see Topping \& Windom, 1977 for techniques) at final concentrations of 5 and $1 \mu \mathrm{g} \mathrm{I}^{-1}$. The experiment ended July 21, and since

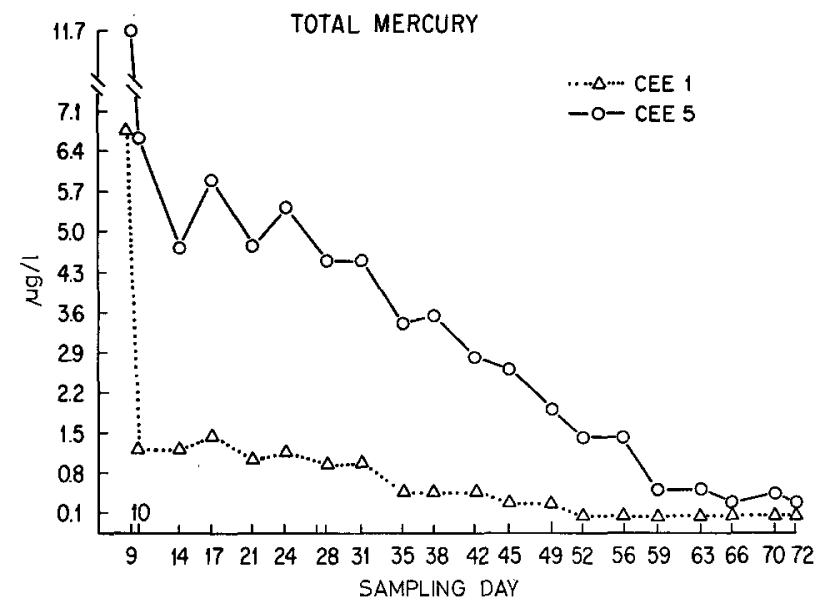

Fig. 2: Total mercury concentrations, $2-18 \mathrm{~m}$

no further metal additions were made, water column concentrations (Fig. 2) decreased approximately at a rate of $2 \%$ /day (Wallace, personal communication), most of it, presumably, being taken up by particulate material and sinking to the bottom. Even in the water column, the majority (over $80 \%$ ) of the metal rapidly became associated with particulate organic matter with a molecular weight exceeding 10,000 (Wallace, personal communication). The CEEs to which 5 and $1 \mu \mathrm{g} \mathrm{l} \mathrm{l}^{-1} \mathrm{Hg}$ were added will be referred to below as CEE 5 and CEE 1 respectively, with the third (uncontaminated) $\mathrm{CEE}$ as the control. The high mercury concentrations observed on day 9 were based on samples taken within $4 \mathrm{~h}$ of addition of the mercury and, consequently reflect initial non-homogenicity in the distribution of the pollutant (Fig. 2).

$$
\begin{gathered}
\text { Heterotrophic micro-organisms and } \\
\text { phytoplankton }
\end{gathered}
$$

Heterotrophic activity of bacteria, as estimated by glucose uptake, followed a similar pattern to that elicited by copper (Vaccaro et al., 1977), namely an immediate 10-fold reduction in activity followed by rapid recovery within five days. 
Changes in the standing crop of phytoplankton throughout the experiment are represented in Figure 3 by a series of particle size distribution spectra (expressed on a vol./vol. basis, i.e. $\mathrm{mm}^{3} \mathrm{1}^{-1}$ or $\mathrm{ppm}$ ) integrated for the entire water column from twice-weekly samples measured using a Coulter model TA II counter. Reeve et al. (1977) showed that there was a high correlation between particle volume and chloro-

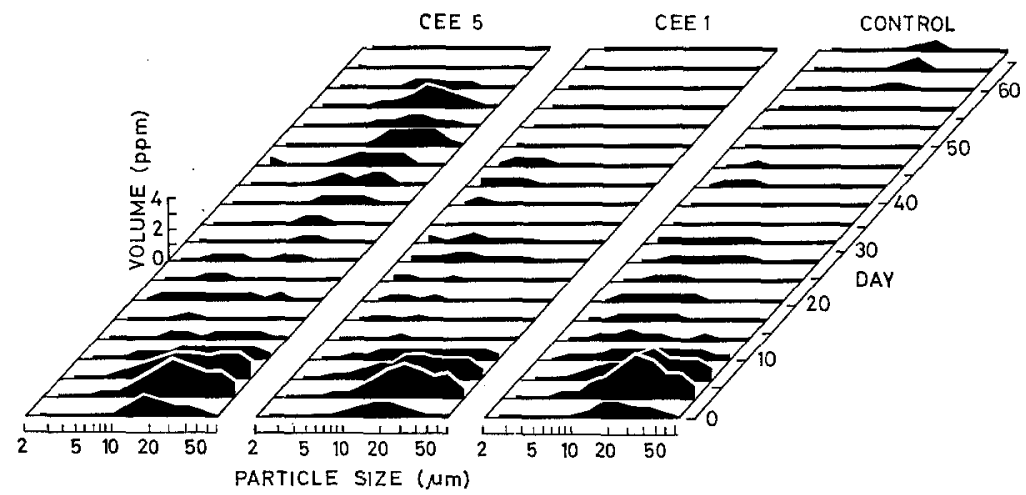

Fig. 3: Particle size spectra for CEEs 5, 1 and control integrated over $20 \mathrm{~m}$ (expressed as volume of particles per volume of water on each sampling day)

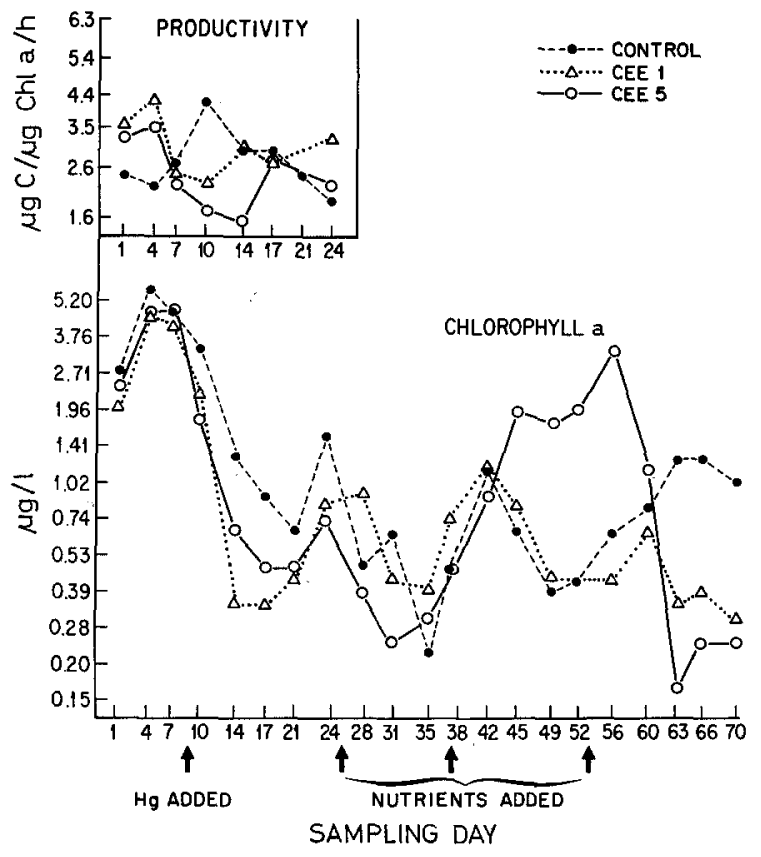

Fig. 4 : Chlorophyll $a$ and productivity, $0-20 \mathrm{~m}$ 
phyll a concentration. Initially, the CEEs captured a moderate (for the region) population of phytoplankton consisting almost entirely of centrate diatoms (Seibert, personal communication) which reached their peak over the second and third sampling days (about $5 \mu \mathrm{g} \mathrm{I}^{-1}$ chlorophyll a). By this time centrate diatoms were already sinking deep in the undisturbed water columns, and were being replaced by smaller flagellates, even before the addition of mercury. This rapid loss of heavy, larger-sized diatom cells is a characteristic of CEEs and is apparently due to the much diminished vertical turbulence (see Introduction).

On three occasions (days $25,37,53$ ) during the experiment, attempts were made to re-seed surface waters with centrate diatoms and their spores by upwelling small amounts of bottom sediments to the surface, and by nutrient addition. This appeared to achieve some success over the middle part of the experiment in CEE 5 (Fig. 4) where chlorophyll a reached $2 \mu \mathrm{g} \mathrm{1}^{-1}$ (integrated $0-20 \mathrm{~m}$ ), but not in the others, for reasons which may be connected with the zooplankton populations (see below). In the case of CEEs 1 and control, standing crop of phytoplankton never again exceeded $1.5 \mu \mathrm{g} \mathrm{l}^{-1}$.

Immediately after the introduction of mercury, the relative rate of carbon assimilation was reduced progressively in the mercury-containing CEEs, as was the standing crop of chlorophyll a (Fig. 4); but both parameters had returned to control levels within a week. This suggested no lasting effect of mercury on the phytoplankton standing crop or production (cf. copper effects at similar concentrations, Thomas et al., 1977).

\section{Zooplanktonsampling techniques}

Due to the relatively small volume of small CEEs $\left(66 \mathrm{~m}^{3}\right)$, zooplankton sampling was limited to filtering $1 \%$ of the entrained water per day. The usual procedure was to make vertical tows with a $20 \mathrm{~cm}$ modified Bongo frame equipped with $202 \mu \mathrm{m}$ mesh nets. Collections were made every three to five days from a depth of $14 \mathrm{~m}$ to the surface. Each net of a pair filtered approximately $0.44 \mathrm{~m}^{3}$ of water and generally three tows were made each sampling day.

Microzooplankton was collected on different days by a small volume pump system. The lack of uniformity in the collection of different size ranges made it impossible to obtain useful estimates of the numbers of life history stages of small copepods which were usually the major zooplankton group. This situation was corrected at the start of the large CEE experiments in 1976 by the introduction of a large volume pump system. The system employed a $2001 \mathrm{~min}^{-1}$, teflon-lined diaphragm pump, $5 \mathrm{~cm}$ internal diameter polyethylene hose and collecting units with 80 and $35 \mu \mathrm{m}$ mesh nets. Simultaneous collection of macro and microzooplankton was made by diverting about $15 \%$ of the flow to the microzooplankton collector. Filtered water was returned to the surface of the CEE to prevent cumulative water loss over the experimental period leading to loss of head and turgidity of the polyethylene column. The hose was lowered into the CEE at a rate which removed about $1 \mathrm{~m}^{3}$ of water over a $16 \mathrm{~m}$ vertical profile. 
Prior to the initiation of the mercury experiment in May 1976, a comparison was made of the numbers and types of organisms obtained in a large CEE by pump and net collecting techniques. Except for Calanus, comparative tests showed that the pumping system was at least as efficient as a net (Fig. 5). The pumping system also permitted an assessment of the patch structure within the CEEs as discussed below.
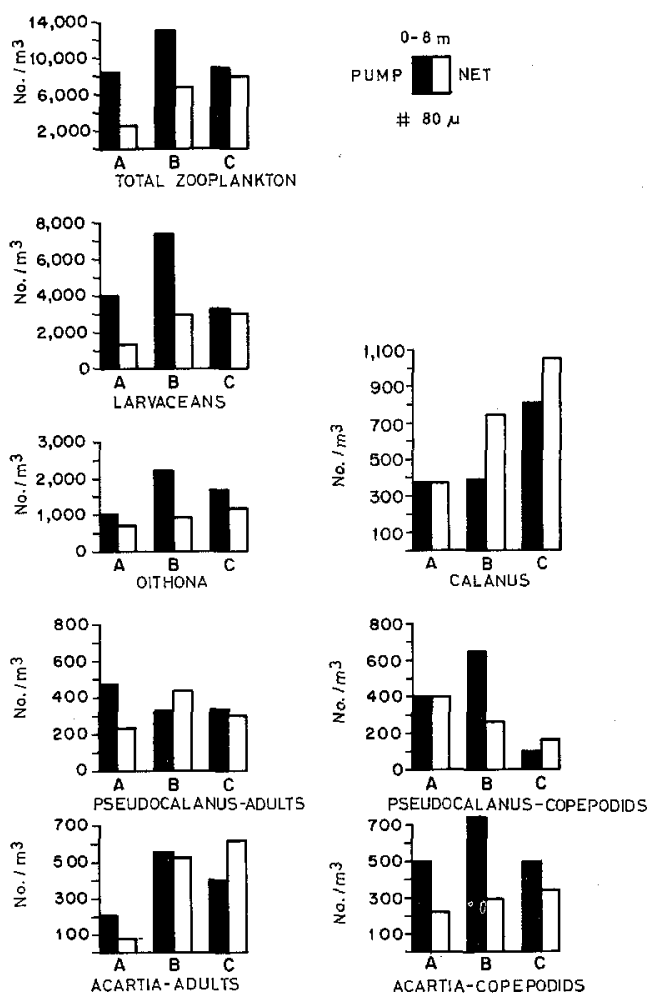

Fig. 5: Comparison of net and pump collections at side (A), center (C) and intermediate position (B)

Bongo nets of $40 \mathrm{~cm}$ diameter were used for obtaining larger organisms such as Calanus and those animals that are rarer, more active or less amenable to passage through a hose, such as ctenophores. Live experimental animals were also obtained in this way. In addition, since populations of the ctenophore Bolinopsis are known to frequently inhabit the lower levels of the water column, a weekly vertical haul was made with a $1 \mathrm{~m}$ diameter $(500 \mu \mathrm{m}$ mesh) net with a large volume cod end designed to minimize damage to the animals.

A typical sampling protocol for zooplankton consisted of a 0 to $16 \mathrm{~m}$ profile at each of three positions situated approximately $1 \mathrm{~m}, 3 \mathrm{~m}$ and $5 \mathrm{~m}$ (center) from the perimeter of the $\mathrm{CEE}$, and an additional three 16 to $20 \mathrm{~m}$ profiles at the center position. The latter collections obtained zooplankton from the cone of the CEE. Bongo 
net collections were made from $16 \mathrm{~m}$ to the surface and a 1 meter net was raised from $20 \mathrm{~m}$. Each CEE was sampled twice weekly for zooplankton.

With the exception of living zooplankton removed from certain net collections for experiments and live counts made for Bolinopsis, all zooplankton was preserved in buffered formalin for taxonomic and quantitative analyses. Preserved samples were divided with a Folsom splitter and macrozooplankton enumerated by species and developmental stages. Microzooplankton samples are being analyzed elsewhere.

\section{Patchiness of plankton}

On several occasions, the vertical distribution of plankton in $1 \mathrm{~m}$ integrated intervals was studied by passing pumped water through a series of $80 \mu \mathrm{m}$ mesh collectors corresponding to the $1 \mathrm{~m}$ depth interval through which the hose was descending. Water samples for particle analysis were also taken. Figure 6 shows the results of one survey for CEE 1 on day 24 when a total of 89 samples were collected between 1200 and $1400 \mathrm{~h}$ in a transect of five vertical profiles across the CEE. Numbers of organisms

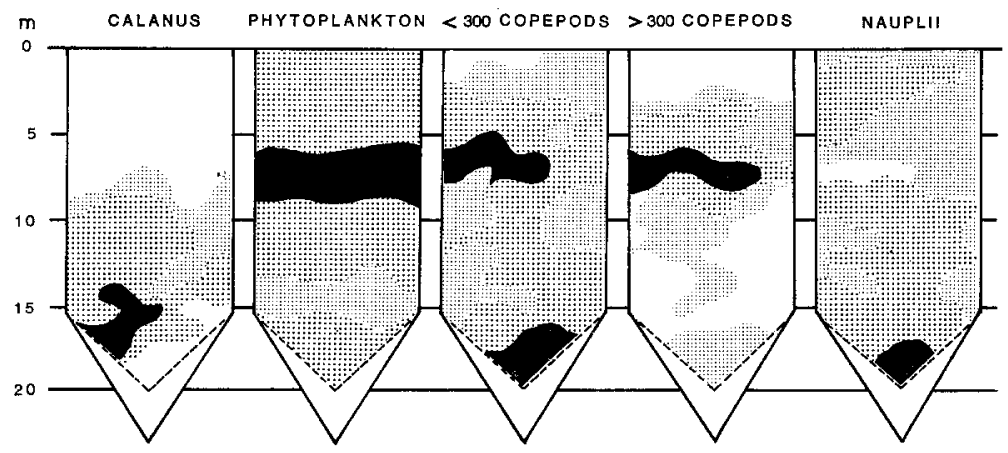

Fig. 6: Patchiness of various catagories of plankton in half-order-of magnitude steps decreasing from dark to light. From left to right the highest concentrations are $100-500 / \mathrm{m}^{3}$ (Calanus); $5 \times 10^{4}-1 \times 10^{5}$ cells $/ \mathrm{ml}$ (phytoplankton); $5 \times 10^{3}-1 \times 10^{4} / \mathrm{m}^{3}$ (copepods greater than $300 \mu \mathrm{m})$; and $1 \times 10^{4}-5 \times 10^{4}$ (copepods less than $300 \mu \mathrm{m}$ and nauplii)

are contoured at half orders of magnitude. The phytoplankton were represented by a bloom of small flagellates in a band concentrated between 6 and $12 \mathrm{~m}$. Calanus was almost absent above $10 \mathrm{~m}$. The remaining copepods, predominantly Pseudocalanus, were separated for analysis into nauplii and earlier copepodid stages which passed through a $300 \mu \mathrm{m}$ mesh net, and later stages which were retained on the net. The latter appeared to be in patches of varying densities throughout the CEE, but the distribution of the younger copepodids was similar to that of the flagellates. The nauplii were relatively uniformly distributed throughout the CEE with peak concentrations near the bottom, perhaps because the sinking eggs would tend to accumulate there. 


\section{Zooplankton populations}

The zooplankton populations captured in the CEEs when the water was entrained were initially quite similar in species composition and numerical abundance. The five most abundant organisms from the $80 \mu \mathrm{m}$ net were Pseudocalanus, Oitbona, Larvaceans, Oncaea and Acartia. The day prior to the addition of mercury the density of zooplankton varied between 14,000 and $21,000 / \mathrm{m}^{3}$; one day after mercury addition the densities were between 13,000 and $16,000 / \mathrm{m}^{3}$. Thereafter the three CEEs diverged considerably, with CEE 5 generally having much smaller numbers of animals.

Copepods represented the primary component of the zooplankton. Table 1 gives the rank order of the major taxa, calculated on the basis of degree of dominance over

Table 1

Rank order of major zooplankton taxa. Taxa were arranged in order of abundance in each CEE and weighted values assigned for each position (20 for the most abundant, 19 for the second, etc.). Values for the whole experiment were summed to find overall rank order

\begin{tabular}{|lcccc|}
\hline \multicolumn{1}{c}{ Taxa } & All CEEs & Control & CEE 1 & CEE $\mathbf{5}$ \\
\hline Pseudocalanus & 1 & 1 & 1 & 1 \\
Oithona & 2 & 2 & 2 & 3 \\
Acartia & 3 & 3 & 3 & 4 \\
Larvacea & 4 & 6 & 10 & 2 \\
Oncaea & 5 & 4 & 4 & 8 \\
Tisbe & 6 & 5 & 6 & 5 \\
Centropages & 7 & 10 & 7 & 10 \\
Gastropoda & 8 & 9 & 5 & 7 \\
Corycaeus & 9 & 8 & 9 & 9 \\
Calanus & 10 & 11 & 11 & \\
Paracalanus & 10 & & & \\
\hline
\end{tabular}

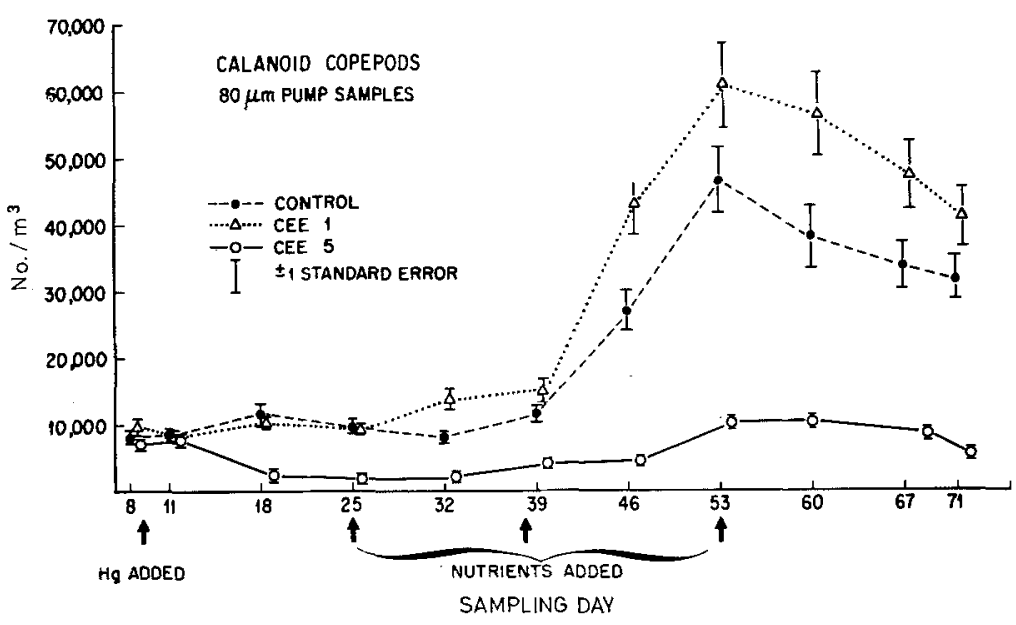

Fig. 7: Calanoid copepod abundance. Density estimates for each sampling day based on the volume - adjusted mean of four samples from each CEE, with a standard error of $\pm 10.98 \%$ 
the course of the experiment. Calanoids were the most numerically important copepods, with the genera Pseudocalanus, Acartia, Centropages, Paracalanus and Calanus included among the top ten ranks. Calanoid abundances (Fig. 7) were derived from analysis of collections from four positions in each CEE: three replicates in the cylinder and one sample in the cone. Variability was found to be nonsignificant with time and among CEEs, permitting a mean percent of \pm 10.98 to be used as the standard error of the estimated density for all mean values.

In the control the numbers of calanoids varied between $8,000 / \mathrm{m}^{3}$ and $12,000 / \mathrm{m}^{3}$ during the first 39 days. Thereafter the numbers increased to a maximum of $46,000 / \mathrm{m}^{3}$ (day 53). Generally densities in the control were between those of CEEs 5 and 1 but much closer to CEE 1 . In CEE 5 the numbers of calanoids decreased from $8,000 / \mathrm{m}^{3}$ on day 11 to $2,500 / \mathrm{m}^{3}$ on day 18 . From day 18 onwards the numbers gradually in-

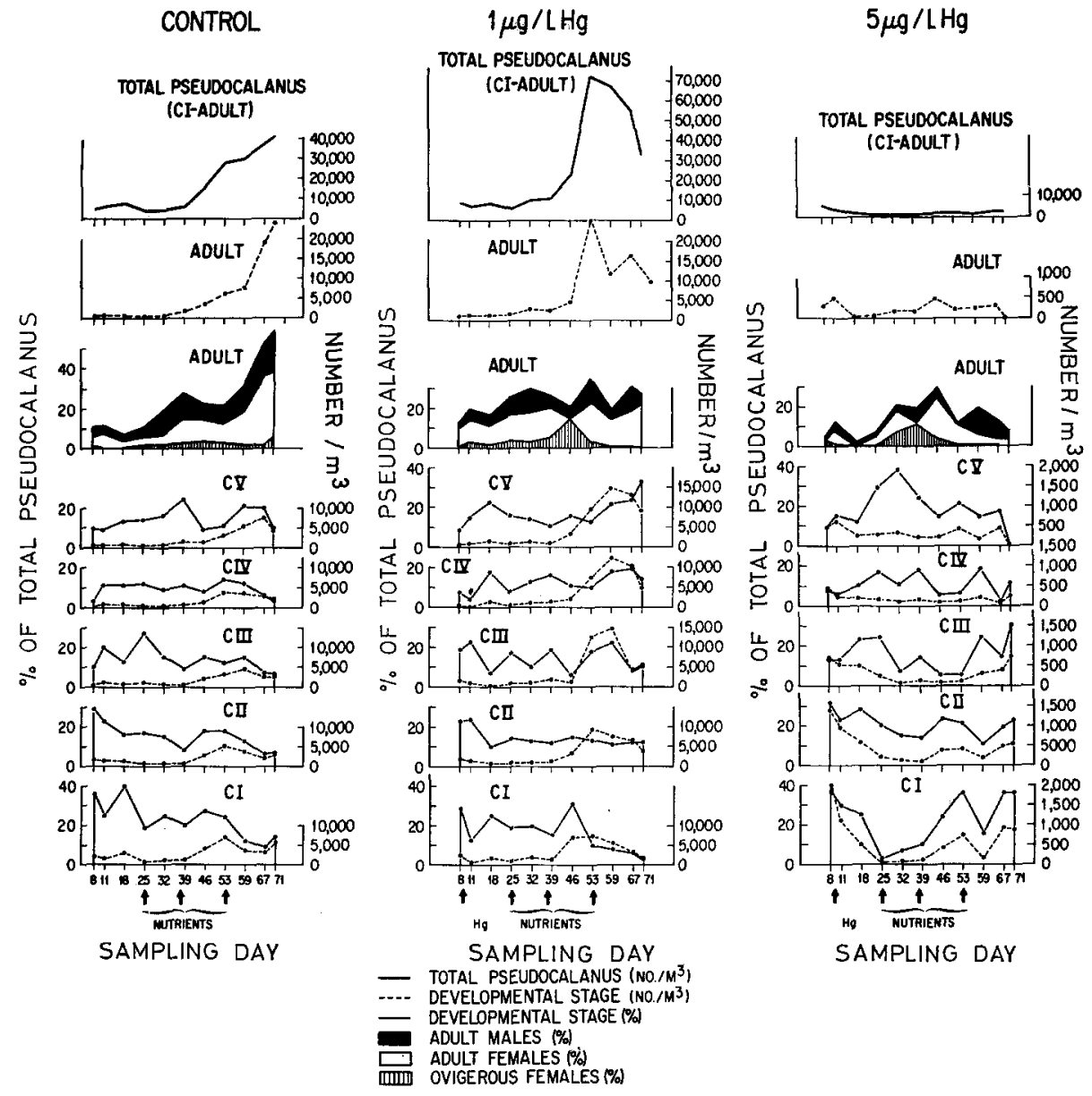

Fig. 8: Population structure and abundance of Pseudocalanus based on collections obtained from the center of the CEEs. Note expanded ordinate scale for CEE 5 
creased to a maximum of $10,000 / \mathrm{m}^{3}$ on day 53 . Throughout the experiment somewhat larger numbers of calanoids were generally present in CEE 1 than in the control. $A$ maximum number of $60,000 / \mathrm{m}^{3}$ was recorded on day 53 in CEE 1 .

Three genera of cyclopoid copepods (Oithona, Oncaea and Corycaeus), and one genus of harpacticoids (Tisbe) were also ranked among the most dominant groups.

During the last month of the experiment the species composition in CEE 5 was very unstable, with a different organism assuming dominance in every sampling period. This was in contrast to the situation in the control and CEE 1, where Pseudocalanus retained dominance, as it had throughout the experiment.

The dynamics of Pseudocalanus, the single most important macrozooplankton genus, has been considered by comparing its abundance and developmental history in the CEEs (Fig. 8). Captured populations were initially quite similar in density of adults (less than $1,000 / \mathrm{m}^{3}$ ) and copepodid stages I, II and III (CI, CII, CIII) were present in decreasing abundance in that order.

In the control CEE, population size remained stable for the first 39 days. By day 46 the numbers of CI and CII had more than doubled, and this was reflected in a subsequent increase in later stages and adults during the next three weeks. The maximum abundance of adults occurred on day 71 , the last day of the experiment.

pseudocalanus in CEE 5 underwent quite different fluctuations. Copepodid stages I, and II exhibited a precipitous decline in abundance during the first 25 days. They remained essentially stable until day 46 when numbers had increased significantly. This rise was reflected to some extent in numbers of CIII, but little increase was noted in later stages. No egg-bearing females were seen between days 11 and 25 in preserved collections in CEE 5 . None were observed after scanning live material collected on day 15 and adult females isolated from the sample did not produce eggs over a 7 day observational period. Stage $V$ females removed from live collections on day 28 , maintained in water from which they were collected, and fed standard phytoplankton ration, failed to molt to adult even after transferral to clean water. On day 50 adult females present in CEE 5 were no different in fecundity than females removed from the other two CEEs. The population structure, the failure of females to molt, and the failure of adults to produce eggs indicate that conditions in CEE 5 prior to day 50 were interfering with reproduction of Pseudocalanus. The decline in CI and CII suggests also that mercury had a greater effect on early developmental stages of the species as has been shown by Reeve et al. (1976) for copepods and other zooplankton in $\mathrm{LD}_{50}$ tests.

In CEE 1 the numbers of CI-CV Pseudocalanus were relatively stable up to day 39. By day 46 the numbers of CI had increased substantially. This increase was later noted in subsequent stages. Egg-bearing females were present throughout, and Stage $V$ females removed from CEE 1 , unlike those from CEE 5, readily molted into adults and produced nauplii.

\section{Zooplankton experimental studies}

The fecal pellet production of the Calanus population was frequently measured in quadruplicate experiments up to day 56. Within six days after the addition of 
mercury, copepods in. CEE 5 showed reductions in feeding relative to the control, which were usually significant (Fig. 9A). Surprisingly, the CEE 1 animals began to show a consistent trend for enhanced pellet production. Experiments were performed in 31 bottles incubated overnight in situ with equal amounts of cultured natural diatom assemblages offered as food. In Figure 9B, Calanus from CEE 5 were transferred to control CEE water, CEE 1 animals were transferred to CEE 5 water, and

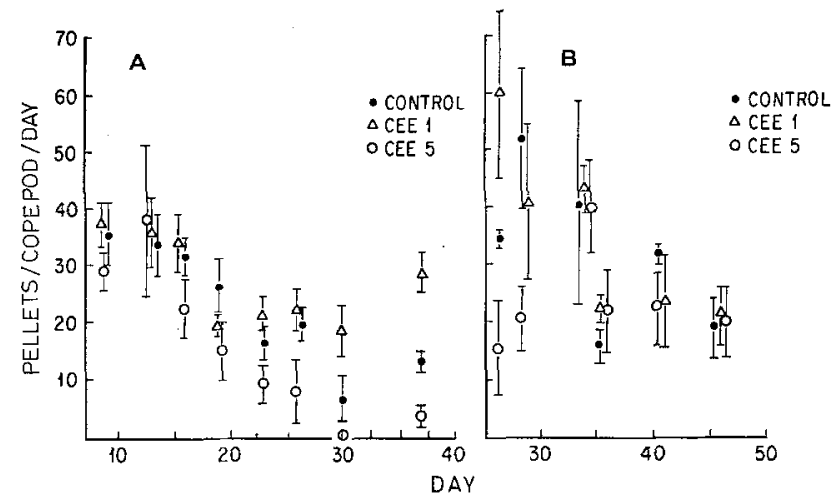

Fig. 9: (A) Fecal pellet production of Calanus in laboratory culture of CEE water. (B) Fecal pellet production of Calanus after transfer of CEE 5 animals to water from control, CEE 1 animals to water from CEE 5 and control animals to water from control. Vertical line is one standard deviation

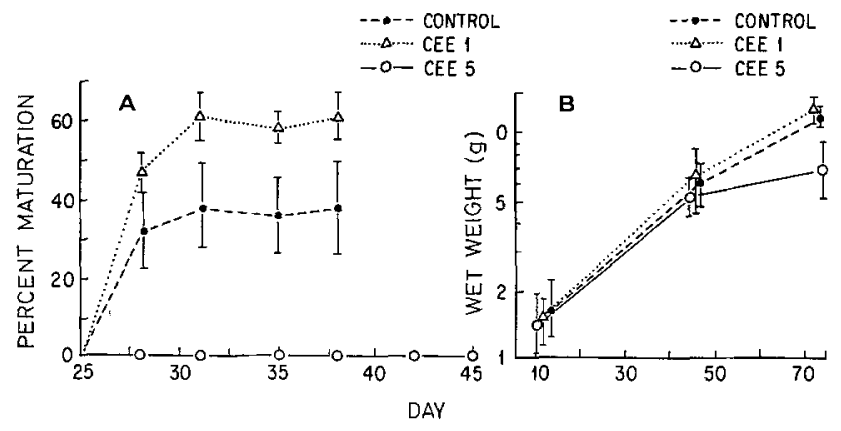

Fig. 10: (A) Molting of stage $\mathrm{V}$ copepodids of Pseudocalanus maintained in the laboratory in water from their respective CEEs. (B) Growth of fingerling Chum salmon. Vertical line is one standard deviation

control animals kept in control water. Fecal pellet production in cultured food was monitored at intervals over 25 days. The CEE 5 animals quickly recovered their feeding ability relative to control animals, but the CEE 1 animals did not suffer any reduction during their exposure to higher mercury levels. It should be noted, however, that mercury in CEE waters was considerably reduced from initial dosed levels.

The maturation and fecundity of Pseudocalanus from the CEEs were also in- 
vestigated. Stage $V$ animals were removed from each CEE on day 28 and kept in the laboratory in water from their respective CEEs with uniform amounts of cultured phytoplankton. Animals from control and CEE 1 matured (Fig. $10 \mathrm{~A}$ ) and produced similar numbers of nauplii per female, although CEE 1 animals matured at a faster rate. The CEE 5 copepods failed to mature even after being transferred to clean water for 11 days after day 35 (Fig. $10 \mathrm{~A}$ ). Adult females from the control and CEE 1 also had similar fecundities between day 39 and 46. On day 51, adult females were available from all three CEEs and all showed comparable fecundity. Furthermore, water from CEE 5 had no effect on the fecundity of control or CEE 1 animals between day 51 and 57. The experiments with small copepods agreed with phenomena seen in the feeding experiments with large copepods in respect to lack of adverse physiological effects in CEE 1, evidence of enhancement in CEE 1 compared to the control, and lack of effects in older CEE 5 water on animals preconditioned to CEE 1 water.

\section{Fish grow th}

Of 55 fingerling Chum salmon placed in each CEE on the day following mercury addition a total of 40,45 and 30 were recovered from control, 1, and 5 CEEs respectively, on three occasions (days 16, 44, 72). Diver reports of fish still remaining uncollected suggested there had been no mortality in any of the CEEs over the entire period. Growth in all CEEs (Fig. 10 B) during the first half of the period was $5 \%$ day. Over the second half of the experiment this rate decreased by half in the control and CEE 1 to $2.5 \%$ /day. The slowing of growth rate is normal as animals get older but could partly be related to diminishing stocks of Calanus. The CEE 5 animals grew at only $0.4 \%$ day, but again the reduced levels of all copepods in this CEE could have been at least partially responsible.

Divers at the end of the experiment estimated that there was a population of roughly 100 other young fish in each CEE which had presumably grown from eggs or larvae captured originally. The largest of these approached the salmon size and were tencatively identified as hake.

Acknowledgements. We wish to thank all members of the CEPEX staff, students and cooperating investigators who participated in the collection of field data and analyses of samples and who contributed experimental data. We also wish to thank J. Chang, $\mathrm{K}$. Darcy, V. R. Gibson, G. Loutitt, M. A. Walter and I. Williams for their assistance in the zooplankton aspects of the program and for their help in the analysis of the data. Dr. Woollcott Smith kindly provided advice and assistance in the statistical treatment of the data. This research was supported by grants OCE 74-05154, GX 39140 and IDOE73-09763 from the office for the International Decade of Ocean Exploration of the U.S. National Science Foundation. This is contribution No. 3909 from the Woods Hole Oceanographic Institution.

\section{LITERATURE CITED}

Case, J., 1977. The engineering aspects of capturing a marine environment, CEPEX and others. Rapp. P.-v. Réun Cons. perm. int. Explor. Mer (In press). 
Menzel, D. W., 1977. Summary of experimental results: controlled ecosystem pollution experiment. Bull. mar. Sci. 27, 142-145.

- \& Case, J., 1977. Concept and design: controlled ecosystem pollution experiment. Bull. mar. Sci. 27, 1-7.

- \& Steele, J. H., 1977. The application of plastic enclosures to the study of pelagic marine biota. Rapp. P.-v. Réun Cons. perm. int. Explor. Mer (In press).

Parsons, T. R., Brockel, K. von, Koeller, P., Takahashi, M., Reeve, M. R. \& Holm-Hansen, O., 1977. The distribution of organic carbon in a marine plankton food web following nutrient enrichment. J. exp. Biol. Ecol. (In press).

Reeve, M. R., Grice, G. D., Gibson, V. R., Walter, M. A., Darcy, K. \& Ikeda, T., 1976. A controlled environmental pollution experiment (CEPEX) and its usefulness in the study of larger marine zooplankton under toxic stress. Effects of pollutants on aquatic organisms. Soc. exp. Biol. Seminar Ser. 2, 145-162.

- \& Walter, M. A., 1976. A large scale experiment on the growth and predation potential of ctenophore populations. In: Coelenterate ecology and behavior. Ed. by G. Mackie. Plenum, New York. 187-199.

- Gamble, J. C. \& Walter, M. A., 1977. Experimental observations on the effects of copper on copepods and other zooplankton: controlled ecosystem pollution experiment. Bull. mar. Sci. 27, 92-104.

Takahashi, M., Thomas, W. H., Seibert, D. L. R., Beers, J., Koeller, P. \& Parsons, T. R., 1975. The replication of biological events in enclosed water columns. Arch. Hydrobiol. 76, 5-23.

Thomas, W. H., Holm-Hansen, O., Seibert, D. L. R., Azam, F., Hodson, R. \& Takahashi, M., 1977. Effects of copper on phytoplankton standing crop and productivity: controlled ecosystem pollution experiment. Bull. mar. Sci. 27, 34-43.

Topping, G. \& Windom, H., 1977. Biological transport of copper at Loch Ewe and Saanich Inlet: controlled ecosystem pollution experiment. Bull. mar. Sci. 27, 134-141.

Vaccaro, R. F., Azam, F. \& Hodson, R. E., 1977. Response of natural marine bacterial populations to copper: controlled ecosystem pollution experiment. Bull. mar. Sci. 27, 17-22.

First author's address: G. D. Grice

Woods Hole Oceanographic Institution

Woods Hole, Massachusetts, 02543

USA 